\title{
Anosognosia in People with Cognitive Impairment: Association with Cognitive Deficits and Behavioral Disturbances
}

\author{
Antonella De Carolis Virginia Cipollini Valentina Corigliano \\ Anna Comparelli Micaela Sepe-Monti Francesco Orzi Stefano Ferracuti \\ Franco Giubilei
}

NESMOS Department, Faculty of Medicine and Psychology, Sapienza University of Rome, Rome, Italy

\author{
Key Words \\ Dementia $\cdot$ Anosognosia $\cdot$ Cognitive impairment $\cdot$ Behavioral symptoms
}

\begin{abstract}
Aims: To investigate, in a group of subjects at an early stage of cognitive impairment, the relationship between anosognosia and both cognitive and behavioral symptoms by exploring the various domains of insight. Methods: One hundred and eight subjects affected by cognitive impairment were consecutively enrolled. The level of awareness was evaluated by means of the Clinical Insight Rating Scale (CIRS). Psychiatric symptoms were evaluated using the Italian version of the Neuropsychiatric Inventory (NPI), whereas memory (memory index, MI) and executive (executive index, EI) functions were explored using a battery of neuropsychological tests and qualified by means of a single composite cognitive index score for each function. Results: A significant positive correlation between the total NPI score and global anosognosia score was found. Furthermore, both the MI and EI scores were lower in subjects with anosognosia than in those without anosognosia ( $p<0.001$ and $p<0.007$, respectively). When the single domains of the CIRS were considered, anosognosia of reason of visit correlated with the EI score $(r=-0.327, p=0.01)$ and night-time behavioral disturbances $(r=0.225 ; p=0.021)$; anosognosia of cognitive deficit correlated with depression $(r=-0.193 ; p=0.049)$ and the MI score $(r=-0.201 ; p=0.040)$; anosognosia of functional deficit correlated with the MI score $(r=-0.257 ; p=0.008)$, delusions $(r=0.232 ; p=0.015)$ and aberrant motor behavior $(r=0.289$; $p=0.003)$; anosognosia of disease progression correlated with the MI score $(r=-0.236 ; p=$ $0.015)$, agitation ( $r=0.247 ; p=0.011)$, aberrant motor behavior $(r=0.351 ; p=0.001$ ) and nighttime behavioral disturbances $(r=0.216$; $p=0.027)$. Conclusions: Our study suggests that, in the early stage of cognitive impairment, anosognosia is associated with both cognitive deficits and behavioral disorders according to the specific functional anatomy of the symptoms.
\end{abstract}




\section{Introduction}

Anosognosia is a major problem in patients affected by dementia because of its implications in various aspects of patient care, such as treatment compliance, personal safety and caregiver distress [1]. Clinician rating is the most widely used method for evaluating awareness deficit, with recent studies confirming the high reliability of this method in patients with Alzheimer's disease (AD) [2].

There is evidence suggesting that anosognosia is correlated with the severity of the cognitive deficit [3-7]. There appears to be some convergence of findings on the involvement of the frontal system in unawareness, particularly in the right hemisphere, as reported in behavioral $[3,8]$ and neuroradiological $[4,9-14]$ studies. Findings on the relationship between unawareness and cognitive domains other than the frontal functions are less consistent, though studies point to the presence of memory deficits $[15,16]$, impaired procedural learning [8] and tendency to intrusions and confabulation [17]. In this regard, we have recently found that the nature of anosognosia in the early stage of cognitive impairment is domain specific and that the cerebral structures underlying memory and executive functions may be involved [18].

Anosognosia in patients with dementia is also related to behavioral disturbances, such as apathy, delusions, depression, anxiety, irritability, agitation and disinhibition, most of which are associated with pathological changes in the frontal lobe [3, 5, 8, 19-24]. However, most of these studies suffer from methodological weaknesses, and few have evaluated all these behavioral disturbances simultaneously $[3,25]$. Furthermore, to our knowledge, no research has yet studied the relationship between behavioral symptoms and specific domains of anosognosia.

The aim of this study was to investigate, in subjects affected by mild cognitive impairment or mild dementia, the relationship between anosognosia in its specific domains and both cognitive and behavioral symptoms. We hypothesize that the specific domains of anosognosia are associated with behavioral and cognitive disturbances. In particular, we intend to find a correlation between the behavioral symptoms related to the dysfunction of frontal structures, such as apathy, disinhibition, delusion, aberrant motor behavior and domains of anosognosia.

\section{Materials and Methods}

One hundred and eight subjects [mean age \pm standard error (SE), $72.5 \pm 0.9$ years; mean education \pm SE, $9.3 \pm 0.4$ years] out of 271 subjects enrolled in a previous study [18] were administered the Neuropsychiatric Inventory (NPI) [26] and were included. All the subjects had a Mini-Mental State Examination (MMSE) [27] score $\geq 21$ and an educational level above 5 years. Subjects who met the clinical criteria for major psychiatric illness according to the DSM-IV-TR [28] were excluded. All the subjects were examined using a comprehensive battery of neuropsychological tests designed to explore several cognitive domains. Prior to the neuropsychological testing, a clinical evaluation of the participants' awareness of their cognitive and functional deficits was performed in order to ensure that self-reports were not biased by their perception of performance in the objective cognitive measures. Written informed consent was obtained from all the participants.

DSM-IV-TR criteria were used for the clinical diagnosis of dementia [28]. According to the international guidelines, 33 subjects $(30.6 \%)$ were identified with probable $(n=25)$ or possible $(n=8)$ AD [29], 11 subjects $(10.2 \%)$ with probable vascular dementia [30], 5 subjects $(4.6 \%)$ with probable frontotemporal dementia [31], 55 (50.9\%) with mild cognitive 
De Carolis et al:: Anosognosia in People with Cognitive Impairment: Association with Cognitive Deficits and Behavioral Disturbances

impairment with a single impaired cognitive domain and 4 subjects (3.7\%) with other diseases consisting of Parkinson's disease $(n=2)$ and Lewy body dementia $(n=2)$.

\section{Assessment of Awareness}

The degree of awareness was evaluated by means of the Clinical Insight Rating Scale (CIRS) [18]. Four domains of patient awareness were assessed: (a) the reason for the visit to the doctor; (b) his/her cognitive deficit, focusing on memory deficit and, to a lesser extent, on impairment of attention and visual-spatial ability; (c) functional deficits in daily living; (d) perception of progression of the deficit/disease. Each of the four domains was ranked from 0 to 2, yielding a total rating from 0 (insight fully preserved) to 8 (insight totally absent). Subjects were subdivided into those 'with anosognosia' (CIRS total score $\geq 1$ ) and those 'without anosognosia' (CIRS total score $=0$ ), apart from the affected domain. The CIRS score was assigned by a blinded physician (V. Corigliano) according to a clinical assessment based on a semi-structured interview with the patient and the caregivers.

\section{Assessment of Cognitive and Behavioral Symptoms}

In accordance with a previous study [18], the following neuropsychological tests were used to evaluate memory and executive functions:

- $\quad$ Rey Auditory Verbal Learning Test - delayed recall 15 min after five learning trials (verbal long-term memory);

- Rey Osterrieth Complex Figure - delayed recall after 15 min (nonverbal long-term memory);

- Phonemic Fluency - total number of words produced beginning with three particular letters (F; P; L) within 1 min (executive functions, verbal modality);

- Trail Making, B-A subtest - differential score between subtest B and subtest A (time in seconds; EI, nonverbal modality).

The raw neuropsychological scores obtained for each subject were converted into standardized scores (z-scores) and summed to create a single composite cognitive index for both memory (memory index, MI) and executive functions (executive index, EI). The sign of the z-score on the Trail Making, B-A subtest was consequently inverted: thus, the lower the index score value, the greater the cognitive domain deficit.

Psychiatric symptoms were evaluated using the Italian version of the NPI [32]. The NPI score was based on a structured interview of a caregiver. Twelve neuropsychiatric disorders were assessed (delusion, hallucination, agitation, dysphoria, anxiety, euphoria, apathy, disinhibition, irritability, aberrant motor behavior, night-time behavioral disturbances and changes in appetite/eating behaviors). The presence of a single neuropsychiatric disturbance was classified on both severity and frequency according to defined criteria. It was ranked from 0 to 4 for frequency and from 0 to 3 for severity, yielding a total rating from 0 (absent) to 12 (most severe). We did not use a cutoff score to categorize the presence/absence of each neuropsychiatric symptom. We considered a neuropsychiatric symptom absent only when its score was equal to 0 .

\section{Statistical Analysis}

All analyses were performed using the Statistical Package for the Social Sciences (SPSS, version 16.0). An independent-sample t test after evaluation of the homogeneity of variance was carried out in order to compare both the presence of behavioral disturbances and the cognitive indexes in subjects with and without anosognosia. Spearman's nonparametric rank correlation was used to assess correlations between variables. Furthermore, the two-tailed partial correlation between anosognosia scores and both cognitive deficits and behavioral disturbances was calculated, adjusting for age, level of education and MMSE value. A stepwise 
Table 1. Behavioral data of the 108 subjects affected by cognitive impairment according to NPI score (mean \pm SE)
Table 2. Demographical variables and cognitive data of the 108 subjects affected by cognitive impairment
De Carolis et al:: Anosognosia in People with Cognitive Impairment: Association with Cognitive Deficits and Behavioral Disturbances

\begin{tabular}{lcr}
\hline & Affected subjects & NPI score \\
\hline Eating disturbances & $43(39.8 \%)$ & $2.2 \pm 0.31$ \\
Delusions & $17(15.7 \%)$ & $0.66 \pm 0.18$ \\
Hallucinations & $7(6.5 \%)$ & $0.43 \pm 0.19$ \\
Agitation/aggression & $37(34.3 \%)$ & $1.86 \pm 0.31$ \\
Depression/dysphoria & $73(67.6 \%)$ & $3.01 \pm 0.34$ \\
Anxiety & $48(44.4 \%)$ & $2.71 \pm 0.37$ \\
Euphoria & $11(10.2 \%)$ & $0.34 \pm 0.12$ \\
Apathy & $63(58.3 \%)$ & $3.38 \pm 0.34$ \\
Disinhibition & $19(17.6 \%)$ & $0.49 \pm 0.14$ \\
Irritability/lability & $60(55.6 \%)$ & $2.7 \pm 0.34$ \\
Aberrant motor activity & $18(16.7 \%)$ & $1.06 \pm 0.25$ \\
Night-time behav. disturb. & $51(47.2 \%)$ & $2.44 \pm 0.3$ \\
\hline
\end{tabular}

\begin{tabular}{lccl}
\hline & $\begin{array}{l}\text { Subjects with } \\
\text { anosognosia } \\
(\mathrm{n}=87)\end{array}$ & $\begin{array}{l}\text { Subjects without } \\
\text { anosognosia } \\
(\mathrm{n}=21)\end{array}$ & $\begin{array}{l}\mathrm{p} \\
\text { value }\end{array}$ \\
\hline Age, years & $74.1 \pm 0.8$ & $65.7 \pm 2.6$ & 0.005 \\
Education, years & $9.5 \pm 0.5$ & $8.5 \pm 0.9$ & 0.328 \\
Males/females & $42 / 45$ & $10 / 11$ & 0.957 \\
MMSE score & $25.1 \pm 0.3$ & $27.2 \pm 0.5$ & 0.01 \\
Trail making, B-A subtest & $450.9 \pm 21.8$ & $273.8 \pm 45.8$ & 0.001 \\
Phonemic fluency & $19.9 \pm 1$ & $23.14 \pm 2.3$ & 0.186 \\
ROCF test - delayed recall & $4 \pm 0.5$ & $7.8 \pm 1.3$ & 0.003 \\
RAVL test -delayed recall & $2.6 \pm 0.3$ & $5.2 \pm 0.7$ & 0.001 \\
\hline
\end{tabular}

Data are presented as mean \pm SE. ROCF $=$ Rey-Osterrieth Complex Figure; RAVL = Rey Auditory Verbal Learning.

multiple regression analysis was also performed, with the anosognosia scores used as the dependent variables and the cognitive/behavioral scores as independent variables. A p value $<0.05$ was considered statistically significant.

\section{Results}

Table 1 shows the behavioral data of subjects divided according to their NPI score. The mean $( \pm$ SE) MMSE score of the subjects was $25.5( \pm 0.2)$, whereas the mean ( \pm SE) MI and EI scores were $0.01( \pm 0.17)$ and $0.03( \pm 0.17)$, respectively. Twenty-one of the 108 subjects did not have any type of anosognosia, whereas the remaining 87 subjects displayed anosognosia in the following domains: reason for visit ( 57 subjects), cognitive deficit (53 subjects), functional deficit ( 50 subjects), disease progression (52 subjects). Table 2 shows the demographical variables and the cognitive data of subjects with and without anosognosia.

A significant positive correlation between the total NPI score and the global anosognosia score emerged (fig. 1). The 87 subjects with at least one domain of anosognosia displayed a significant increase in agitation, hallucination, euphoria, irritability, aberrant motor activity and night-time behavioral disturbances (fig. 2). Furthermore, both the MI and EI scores were lower in subjects with anosognosia (mean value \pm SE, $-0.28 \pm 0.18$ and $-0.19 \pm 0.18$, respectively) than in those without anosognosia ( $1.22 \pm 0.38$ and $0.96 \pm 0.38$, respectively; $p=0.001$ 
De Carolis et al.: Anosognosia in People with Cognitive Impairment: Association with

Fig. 1. Scatter plot showing the relationship between the total NPI score and the global anosognosia score in 108 subjects affected by cognitive impairment $(\mathrm{r}=$ $0.528, \mathrm{p}=0.001$; Spearman's correlation test).

Fig. 2. Bar graph showing the presence of behavioral disturbances (mean value \pm SE) in 87 subjects with cognitive impairment and anosognosia compared to 21 subjects with cognitive impairment without anosognosia ${ }^{*} \mathrm{p}<0.05,{ }^{* *} \mathrm{p}<0.005$, unpaired Student's t test).
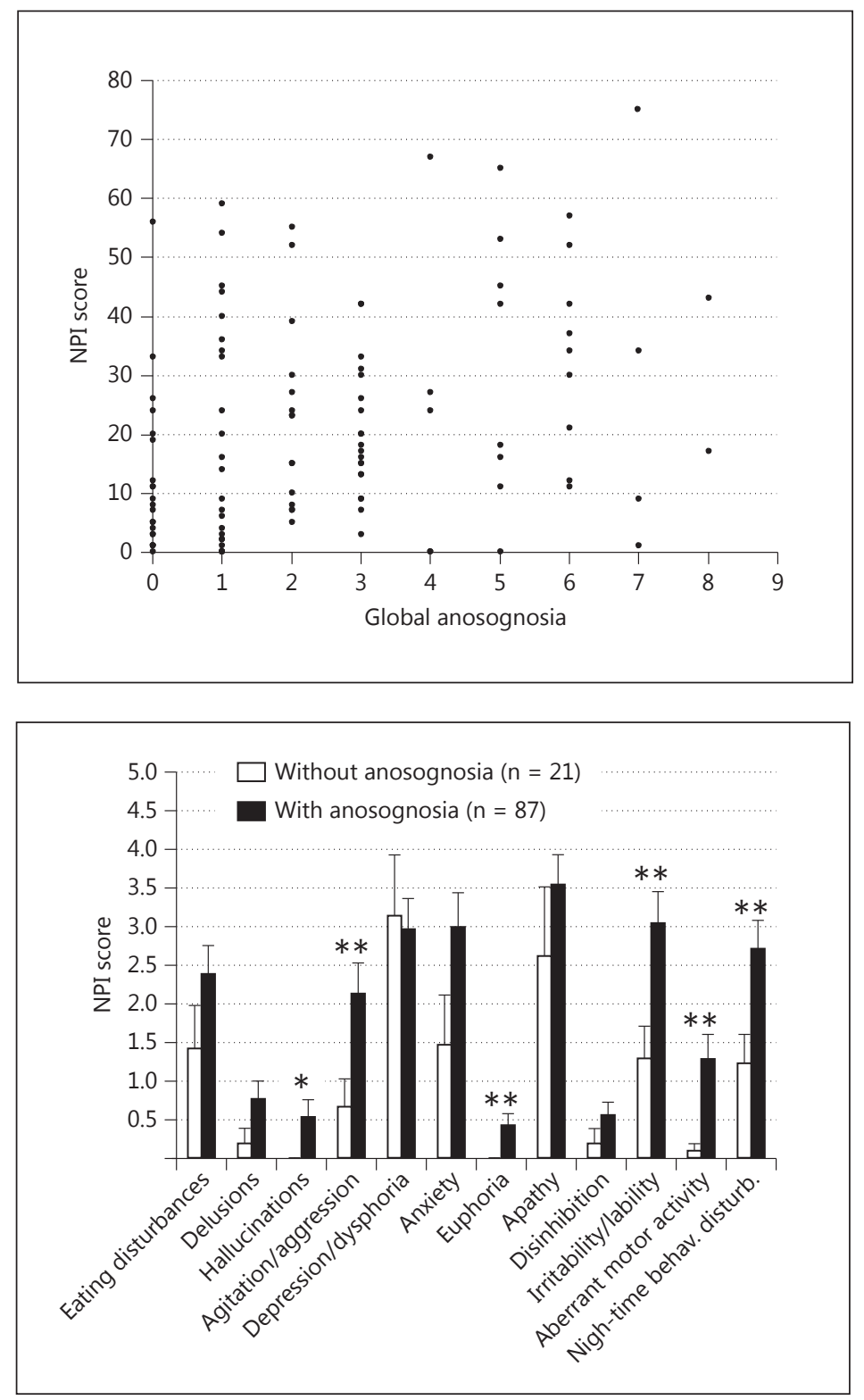

and $\mathrm{p}=0.007$, unpaired Student's t test). When the single domains of the CIRS were considered, anosognosia of reason for the visit was correlated with the EI score $(r=-0.327 ; p=0.001)$ and night-time behavioral disturbances $(r=0.225 ; \mathrm{p}=0.021)$; anosognosia of cognitive deficit was correlated with depression ( $r=-0.193 ; \mathrm{p}=0.049)$ and $\mathrm{MI}(\mathrm{r}=-0.201 ; \mathrm{p}=0.040)$; anosognosia of functional deficit was correlated with MI ( $r=-0.257 ; p=0.008)$, delusions ( $r=0.232$; $\mathrm{p}=0.015)$ and aberrant motor behavior $(\mathrm{r}=0.289$; $\mathrm{p}=0.003)$; lastly, anosognosia of disease progression was correlated with MI $(r=-0.236 ; p=0.015)$, agitation $(r=0.247 ; p=0.011)$, aberrant motor behavior $(\mathrm{r}=0.351 ; \mathrm{p}=0.001)$ and night-time behavioral disturbances $(\mathrm{r}=$ $0.216 ; \mathrm{p}=0.027$; table 3).

Multiple regression analysis revealed that MI and aberrant motor behavior were predictors of the global score of anosognosia $(\beta=-0.319, p=0.001$ and $\beta=0.318, p<0.001$, respectively; $\mathrm{R}^{2}=0.268$ ). With regard to the specific types of anosognosia, we found that EI 
Table 3. Correlation (Spearman's correlation test) between anosognosia evaluated according to the single domains of the CIRS and the NPI scores and cognitive indexes

\begin{tabular}{|c|c|c|c|c|c|c|c|c|}
\hline & \multicolumn{2}{|c|}{$\begin{array}{l}\text { Anosognosia of } \\
\text { reason for visit }\end{array}$} & \multicolumn{2}{|c|}{$\begin{array}{l}\text { Anosognosia of } \\
\text { cognitive deficit }\end{array}$} & \multicolumn{2}{|c|}{$\begin{array}{l}\text { Anosognosia of } \\
\text { functional deficit }\end{array}$} & \multicolumn{2}{|c|}{$\begin{array}{l}\text { Anosognosia of } \\
\text { disease progression }\end{array}$} \\
\hline & r value & $\mathrm{p}$ value & $r$ value & $\mathrm{p}$ value & r value & $\mathrm{p}$ value & r value & $\mathrm{p}$ value \\
\hline Eating disturbances & -0.004 & 0.967 & 0.073 & 0.461 & 0.127 & 0.197 & 0.112 & 0.256 \\
\hline Delusions & -0.036 & 0.719 & 0.001 & 0.999 & 0.232 & 0.015 & 0.128 & 0.192 \\
\hline Hallucinations & 0.072 & 0.468 & 0.087 & 0.377 & 0.187 & 0.056 & 0.191 & 0.051 \\
\hline Agitation/aggression & -0.042 & 0.667 & 0.084 & 0.394 & 0.191 & 0.051 & 0.247 & 0.011 \\
\hline Depression/dysphoria & 0.027 & 0.785 & -0.193 & 0.049 & -0.179 & 0.068 & -0.156 & 0.112 \\
\hline Anxiety & 0.070 & 0.481 & 0.104 & 0.289 & 0.089 & 0.364 & 0.187 & 0.056 \\
\hline Euphoria & 0.005 & 0.960 & 0.049 & 0.617 & 0.008 & 0.933 & -0.077 & 0.434 \\
\hline Apathy & 0.021 & 0.832 & 0.178 & 0.070 & 0.117 & 0.234 & 0.124 & 0.209 \\
\hline Disinhibition & -0.052 & 0.600 & 0.006 & 0.948 & 0.142 & 0.147 & 0.054 & 0.583 \\
\hline Irritability/lability & 0.041 & 0.676 & 0.065 & 0.513 & 0.141 & 0.151 & -0.002 & 0.985 \\
\hline Aberrant motor activity & 0.040 & 0.684 & 0.156 & 0.113 & 0.289 & 0.003 & 0.351 & 0.001 \\
\hline Night-time behav. disturb. & 0.225 & 0.021 & 0.054 & 0.585 & 0.130 & 0.186 & 0.216 & 0.027 \\
\hline MI & -0.038 & 0.701 & -0.201 & 0.040 & -0.257 & 0.008 & -0.236 & 0.015 \\
\hline EI & -0.327 & 0.001 & -0.085 & 0.389 & -0.045 & 0.646 & -0.028 & 0.777 \\
\hline
\end{tabular}

Figures in bold indicate $\mathrm{p}<0.05$, statistically significant difference.

and night-time behavioral disturbances were predictors of anosognosia of reason for the visit $\left(\beta=-0.347, p=0.001\right.$ and $\beta=0.201, p=0.026$, respectively; $\left.R^{2}=0.174\right)$; MI was a predictor of anosognosia of cognitive deficit $\left(\beta=-0.327, p=0.001 ; R^{2}=0.107\right)$; MI, aberrant motor behavior and delusions were predictors of anosognosia of functional deficit $(\beta=-0.272, p=$ $0.003, \beta=0.244, p=0.008$, and $\beta=0.220, p=0.013$, respectively; $R^{2}=0.277$ ); lastly, $\mathrm{MI}$ and aberrant motor behavior were predictors of anosognosia of disease progression $(\beta=-0.278$, $p=0.003$, and $\beta=0.314, p=0.001$, respectively; $R^{2}=0.232$ ).

\section{Discussion}

Our results suggest that insight in mild cognitive deterioration is significantly associated with both the pattern of the cognitive impairment and the presence of specific behavioral disorders. Furthermore, they confirm that the relationship between clinical features and the level of awareness is domain specific, which is in accordance with the hypothesis that awareness is not an all-or-nothing phenomenon. Data regarding the MMSE score suggest that the presence of anosognosia may be due to the degree of cognitive impairment. In this regard, the results of our previous study showed that the relationship between the severity of cognitive deficits and anosognosia is partial and depends on the specific domain of unawareness [18]. On the other hand, we found a correlation between the total NPI score and the global anosognosia score.

We found that memory deficits and aberrant motor behavior are the best predictors of the variance of global anosognosia as well as anosognosia of both functional impairment and disease progression. It can be argued that we did not use corrections in the assessment of multiple correlations. In this regard, as this study is preliminary and exploratory, a more conservative choice was adopted. Our results may be conceptualized within the framework of current neurocognitive models of anosognosia. According to the Cognitive Awareness 
De Carolis et al:: Anosognosia in People with Cognitive Impairment: Association with Cognitive Deficits and Behavioral Disturbances

Model developed for the memory deficit in AD [33-37], unawareness derives from three functional components: a failure to update self-knowledge following damage to the hippocampus and the medial temporal lobe; a gradual loss of personal semantic information, as a consequence of damage to the parietal, temporal and prefrontal cortices; lastly, a frontal lobe dysfunction, which involves error monitoring, failure of episodic memory retrieval and impairment of the belief evaluation system. Judgment about current condition implies the integration of elements from episodic and semantic memory other than the engagement of a monitoring and evaluative system, thus suggesting that metacognitive processing is highly complex. These anatomical structures are the same as those involved in the impairment of long-term memory and aberrant motor behavior [38, 39], and the correlation that emerged between global anosognosia and total NPI score should not be considered surprising. Indeed, psychotic symptoms and aberrant behaviors during the night have been related to neuropathological changes in the right frontal and related subcortical structures [21, 40].

In keeping with our previous results [18], anosognosia of cognitive impairment depends on memory deficit alone, which implies that the only structures involved in the entire metacognitive circuit of unawareness are the mesial temporal structures. By contrast, anosognosia of reason for the visit depends on a dysfunction of the frontal structures. Indeed, our data show that a deficit in executive functions and aberrant behavior during the night are the best predictors of the variance of this kind of anosognosia. In this regard, functional studies have shown that sleep disorders, as measured by means of the NPI, are associated with atrophy/ dysfunction of the temporal, amygdala and ventromedial frontal cortical regions [40].

It is noteworthy that the neuropsychological EI and aberrant behavior during the night are not related to each other. According to current theories, the frontal lobe is organized in distinct parallel circuits that connect cortical regions with specific subregions of the striatum, globus pallidus and thalamus. Executive functions in particular, i.e. reduced verbal and nonverbal fluency, impaired mental control and perseveration, are supported by the dorsolateral prefrontal-subcortical circuit, whereas behavioral symptoms are related to damage in the orbitofrontal- and medial frontal-subcortical circuits [41]. These considerations may also explain the apparent discrepancy between the findings that emerge from this study and those of our previous work, in which we did not find any relationship between frontal structure dysfunction and anosognosia of functional deficits or disease course [18]. Indeed, in our previous work we did not evaluate behavioral symptoms, nor did we investigate the role of orbitofrontal- and medial frontal-subcortical circuits in anosognosia.

We found that dysphoria, as measured by the NPI, is inversely correlated with anosognosia of cognitive deficit, suggesting that the greater the severity of the psychiatric symptom, the lower the unawareness of the cognitive deficits. This is in keeping with previous studies that have reported a relationship between less severe forms of depression, such as dysthymia, and a higher awareness of a deficit, indicating that dysthymia may be a psychological reaction to the changes associated with the disease $[8,22]$. The relationship between depressive symptoms and anosognosia is, however, a matter of debate [5, 42-44]. These conflicting results may be due to the influence exerted on some symptoms associated with depression (e.g. apathy, lack of initiation) by the dysfunction of certain brain systems [45, 46]. In particular, apathy in $\mathrm{AD}$ is associated with alterations in the anterior cingulate, which is closely related to functions such as error monitoring [44].

This study has several limitations: we did not assess long-term memory to evaluate the function of mesial temporal structures separately from that of prefrontal structures; moreover, we did not study the role of a possible right hemispheric lateralization of anosognosia, nor did we assess a possible influence of the subjects' premorbid general intellectual level; lastly, the number of cognitive tests was limited and the sample was heterogeneous. In this regard, we used a sample of subjects with a range of clinical diagnoses to mitigate the potential 
De Carolis et al:: Anosognosia in People with Cognitive Impairment: Association with Cognitive Deficits and Behavioral Disturbances

biases of disease-specific effects on deficits of insight and to obtain findings that may be applied as widely as possible.

In conclusion, the present study suggests that, in mild cognitive deterioration, anosognosia is associated with cognitive deficits and behavioral disorders, according to the specific functional anatomy of the symptoms. Anosognosia seems to depend on the dysfunction of an extensive neural network including the frontal and temporal structures, which play different roles in the specific domains of anosognosia. Furthermore, our data support the hypothesis that frontal structures may cause anosognosia through the involvement of different corticosubcortical neuronal networks: the orbital-frontal and mesial-frontal circuits are likely to be involved in all domains of anosognosia, with the exception of cognitive deficit, whereas the influence of the dorsolateral circuit appears to be more limited, it being involved exclusively in anosognosia of reason for visit. Neuroimaging studies, however, are needed to better understand the neural network involved in the specific domains of anosognosia and its influence on cognitive and behavioral disorders in subjects affected by cognitive deterioration.

\section{References}

1 Rosen HJ: Anosognosia in neurodegenerative disease. Neurocase 2011;17:231-241.

-2 Okonkwo OC, Spitznagel MB, Alosco ML, Tremont G: Association among measures of awareness of cognitive deficits in dementia. Alzheimers Dement 2010;6:312-318.

-3 Kashiwa Y, Kitabayashi Y, Narumoto J, Nakamura K, Ueda H, Fukui K: Anosognosia in Alzheimer's disease: association with patient characteristics, psychiatric symptoms and cognitive deficits. Psychiatry Clin Neurosci 2005;59:697-704.

$>4$ Vogel A, Hasselbalch SG, Gade A, Ziebell M, Waldemar G: Cognitive and functional neuroimaging correlate for anosognosia in mild cognitive impairment and Alzheimer's disease. Int J Geriatr Psychiatry 2005;20:238-246.

5 Harwood DG, Sultzer DL, Wheatley MV: Impaired insight in Alzheimer disease: association with cognitive deficits, psychiatric symptoms and behavioural disturbances. Neuropsychiatry Neuropsychol Behav Neurol 2000;13:83-88.

-6 Starkstein SE, Jorge R, Mizrahi R, Robinson RG: A diagnostic formulation for anosognosia in Alzheimer's disease. J Neurol Neurosurg Psychiatry 2006;77:719-725.

7 Vogel A, Stokholm J, Gade A, Andersen BB, Hejl A, Waldemar G: Awareness of deficits in mild cognitive impairment and Alzheimer's disease: do MCI patients have impaired insight? Dement Geriatr Cogn Disord 2004;17:181-187.

-8 Starkstein SE, Sabe L, Cuerva AG, Kuzis G, Leiguarda R: Anosognosia and procedural learning in Alzheimer's disease. Neuropsychiatry Neuropsychol Behav Neurol 1997;10:96-101.

-9 Harwood DG, Sultzer DL, Feil D, Monserratt L, Freedman E, Mandelkern M: Frontal lobe hypometabolism and impaired insight in Alzheimer Disease. Am J Geriatr Psychiatry 2005;13:934-941.

10 Salmon E, Perani D, Herholz K, Marique P, Kalbe E, Holthoff V, Delbeuck X, Beuthien-Baumann B, Pelati O, Lespagnard S, Collette F, Garraux G: Neural correlates of anosognosia for cognitive impairment in Alzheimer's disease. Hum Brain Mapp 2006;27:588-597.

11 Hanyu H, Sato T, Akai T, Shimizu S, Hirao K, Kanetaka H, Iwamoto T, Koizumi K: Neuroanatomical correlates of unawareness of memory deficits in early Alzheimer's disease. Dement Geriatr Cogn Disord 2008;25:347353.

12 Rosen HJ, Alcantar O, Rothlind J, Sturm V, Kramer JH, Weiner M, Miller BL: Neuroanatomical correlates of cognitive self-appraisal in neurodegenerative disease. Neuroimage 2010;49:3358-3364.

13 Mimura M, Yano M: Memory impairment and awareness of memory deficits in early-stage Alzheimer's disease. Rev Neurosci 2006; 17:253-266.

14 Zamboni G, Grafman J, Krueger F, Knutson KM, Huey ED: Anosognosia for behavioral disturbances in frontotemporal dementia and corticobasal syndrome: a voxel-based morphometry study. Dement Geriatr Cogn Disord 2010;29:88-96.

15 Migliorelli R, Tesòn A, Sabe L, Petracca G, Petracchi M, Leiguarda R, Starkstein SE: Anosognosia in Alzheimer's disease: a study of associated factors. J Neuropsychiatry Clin Neurosci 1995;7:338-344.

16 Souchay C, Isingrini M, Gil R: Alzheimer's disease and feeling-of-knowing in episodic memory. Neuropsychologia 2002;40:2386-2396.

17 Dalla Barba G, Parlato V, Iavarone A, Boller F: Anosognosia, intrusions and 'frontal' functions in Alzheimer's disease and depression. Neuropsychologia 1995;33:247-259.

18 De Carolis A, Corigliano V, Comparelli A, Sepe-Monti M, Cipollini V, Orzi F, Ferracuti S, Giubilei F: Neuropsychological patterns underlying anosognosia in people with cognitive impairment. Dement Geriatr Cogn Disord 2012;34:216-223. 
De Carolis et al.: Anosognosia in People with Cognitive Impairment: Association with Cognitive Deficits and Behavioral Disturbances

19 Starkstein SE, Petracca G, Chemerinski E, Kremer J: Syndromic validity of apathy in Alzheimer's disease. Am J Psychiatry 2001;158:872-877.

20 Robert PH, Clairet S, Benoit M, Koutaich J, Bertogliati C, Tible O, Caci H, Borg M, Brocker P, Bedoucha P: The apathy inventory: assessment of apathy and awareness in Alzheimer's disease, Parkinson's disease and mild cognitive impairment. Int J Geriatr Psychiatry 2002;17:1099-1105.

21 Mega MS, Lee L, Dinov ID, Mishkin F, Toga AW, Cummings JL: Cerebral correlate of psychotic symptoms in Alzheimer's disease. J Neurol Neurosur Psychiatry 2000;69:167-171.

22 Aalten P, van Valen E, de Vugt ME, Lousberg R, Jolles J, Verhey FR: Awareness and behavioural problems in dementia patients: a prospective study. Int Psychogeriatr 2006;18:1-17.

23 Starkstein SE, Brockman S, Bruce D, Petracca G: Anosognosia is a significant predictor of apathy in Alzheimer's disease. J Neuropsychiatry Clin Neurosci 2010;22:378-383.

24 Verhülsdonk S, Quack R, Höft B, Lange-Asschenfeldt C, Supprian T: Anosognosia and depression in patients with Alzheimer's dementia. Arch Gerontol Geriatr 2013;57:282-287.

25 Spalletta G, Girardi P, Caltagirone C, Orfei MD: Anosognosia and neuropsychiatric symptoms and disorder in mild Alzheimer disease and mild cognitive impairment. J Alzheimers Dis 2012;29:761-772.

-26 Cummings JL: The neuropsychiatric inventory: assessing psychopathology in dementia patients. Neurology 1997;48(suppl 6):S10-S16.

-27 Folstein MF, Folstein SE, McHugh PR: 'Mini-mental state'. A practical method for grading the cognitive state of patients for the clinician. J Psychiatr Res 1975;12:189-198.

28 American Psychiatric Association: Diagnostic and Statistical Manual of Mental Health Disorders, ed 4, text revision. Washington, American Psychiatric Association, 2000.

29 McKhann G, Drachman D, Folstein M, Katzman R, Price D, Stadlan EM: Clinical diagnosis of Alzheimer's disease: report of NINCDS-ADRDA Work Group under the auspices of Department of Health and Human Service Task Force on Alzheimer's Disease. Neurology 1984;34:939-944.

-30 Roman GC, Tatemichi TK, Erkinjuntti T, Commings JC, Masdeu JC, Garcia JH, Amaducci L, Orgogozo SM, Brun A, Hofman A: Vascular dementia: diagnostic criteria for research studies. Report of the NINDS-AIREN International Workshop. Neurology 1993;43:250-260.

-31 Englund B, Brun A, Gustafson L, Passant U, Mann DMA, Neary D, Snowden JS: Clinical and neuropathological criteria for frontotemporal dementia. The Lund and Manchester Groups. J Neurol Neurosurg Psychiatry 1994; 57:416-418.

32 Binetti G, Mega MS, Magni E, Padovani A, Rozzini L, Bianchetti A, Trabucchi M, Cummings JL: Behavioral disorders in Alzheimer disease: a transcultural perspective. Arch Neurol 1998;55:539-544.

-33 Mograbi DC, Brown RG, Morris RG: Anosognosia in Alzheimer's disease - the petrified self. Conscious Cogn 2009;18:989-1003.

34 Agnew SK, Morris RG: The heterogeneity of anosognosia for memory impairment in Alzheimer's disease: a review of the literature and a proposed model. Aging Mental Health 1998;2:7-19.

35 Morris R, Hannesdottir K: Loss of awareness in Alzheimer's disease; in Morris R, Becker J (eds): Cognitive Neuropsychology of Alzheimer's Disease, ed 2. Oxford, Oxford University Press, 2004, pp 275-296.

-36 Rosen HJ: Anosognosia in neurodegenerative disease. Neurocase 2011;17:231-241.

-37 Mograbi DC, Morris RG: Implicit awareness in anosognosia: clinical observations, experimental evidence, and theoretical implications. Cogn Neurosci 2013;4:181-197.

38 Simons JS, Spiers HJ: Prefrontal and medial temporal lobe interactions in long-term memory. Nat Rev Neurosci 2003;4:637-648.

39 Rosen HJ, Allison SC, Schauer GF, Gorno-Tempini ML, Weiner MW, Miller BL: Neuroanatomical correlates of behavioural disorders in dementia. Brain 2005;128:2612-2625.

40 Liu W, Miller BL, Kramer JH, Rankin K, Wyss-Coray C, Gearhart R, Phengrasamy L, Weimer M, Rosen HJ: Behavioral disorders in the frontal and temporal variants of frontotemporal dementia. Neurology 2004;62:742-748.

41 Cummings JL: Anatomic and behavioral aspects of frontal-subcortical circuits. Ann NY Acad Sci 1995;769: $1-13$.

42 Smith CA, Henderson VW, McCleary CA, Murdock GA, Buckwalter JG: Anosognosia and Alzheimer's disease: the role of depressive symptoms in mediating impaired insight. J Clin Exp Neuropsychol 2000;22:437-444.

43 Arkin S, Mahendra N: Insight in Alzheimer's patients: results of a longitudinal study using three assessment methods. Am J Alzheimers Dis Other Demen 2001;16:211-224.

44 Mograbi DC, Morris RG: On the relation among mood, apathy, and anosognosia in Alzheimer's disease. J Int Neuropsychol Soc 2014;20:2-7.

45 Aalten P, van Valen E, Clare L, Kenny G, Verhey F: Awareness in dementia: a review of clinical correlates. Aging Ment Health 2005;9:414-422.

-46 Ecklund-Johnson E, Torres I: Unawareness of deficits in Alzheimer's disease and other dementias: operational definitions and empirical findings. Neuropsychol Rev 2005;15:147-166. 